RASĀYAN J. Chem.

Vol. 13 | No. 3 |1829-1833| July - September | 2020 ISSN: 0974-1496 | e-ISSN: 0976-0083 | CODEN: RJCABP http://www.rasayanjournal.com http://www.rasayanjournal.co.in

\title{
ADSORPTION OF HEXAVALENT CHROMIUM BY ACTIVATED CHARCOAL PREPARED FROM Phyllanthus emblica TREE BARK
}

\author{
A. R. Somwanshi ${ }^{1, *}$ and U.E. Chaudhari ${ }^{2}$ \\ ${ }^{1}$ Department of Chemistry, Shri Shivaji Arts, Commerce and Science College, \\ Akot-444101, India \\ ${ }^{2}$ Department of Chemistry, Mahatma Fule Arts, Commerce and Sitaramji Chaudhari Science \\ College, Warud-444906, INDIA \\ *E-mail: anilsomwanshi40@gmail.com
}

\begin{abstract}
The paper deals with the study of for the adsorption of $\mathrm{Cr}$ (VI) using low-cost adsorbent activated charcoal prepared from Phyllanthus Emblica tree bark (AC-PETB). Batch adsorption method has been employed for the removal of Chromium (VI). The various parameters like adsorption dose, contact time, $\mathrm{pH}$, etc have been studied in batch adsorption method. Langmuir and Freundlich's isotherms are used for the evaluation of equilibrium adsorption studies. To enhance the adsorption capacity of activated carbon, it is loaded with Sodium lauroyl sarcosinate and 2Acrylamido-2-methylpropane sulfonic acid and compared the adsorption capacity. The maximum removal efficiency for the removal of $\mathrm{Cr}$ (VI) found to be at $\mathrm{pH}$ 2. Activated charcoal loaded with 2-Acrylamido-2methylpropane sulfonic acid found to be most effective for the removal of $\mathrm{Cr}$ (VI) compared with the charcoal loaded with Sodium lauroyl sarcosinate and virgin activated charcoal.
\end{abstract}

Keywords: Chromium (VI), Adsorption, Phyllanthus emblica, Langmuir, Freundlich

(C) RASĀYAN. All rights reserved

\section{INTRODUCTION}

Activated carbon prepared from biomass is more effective and widely used for the removal of many heavy metal ions because of its highly porous nature and availability of surface area. This factor increases the adsorption capacity of activated charcoal and shows excellent adsorption capacity. From more than three decades activated charcoal is used for the reclamation of wastewater which comes from the industries and municipal corporation ${ }^{1}$. Chromium (VI) is more toxic when it releases into the environment. Chromium is present in the hexavalent and trivalent form. The trivalent form of chromium is less toxic as compared to the hexavalent form. Now a day's researchers focus on low-cost bio adsorbents like sawdust, rice husk, coconut shell and activated charcoal prepared from various tree bark ${ }^{2}$. Many methods have been used for the removal of heavy metals that include chemical precipitation, ion exchange, cementation, coagulation and flocculation, complexation, biosorption, and membrane processes $^{3-5}$. These methods produce by-products in the form of sludge and for the decomposition of this sludge required operational cost, because of that these methods are not suitable for small scale industries. Adsorption is an easy and cheap process which requires low operation cost for the removal of dyes and heavy metal ions ${ }^{6}$. The literature revealed that activated carbon has a high surface area, high porosity which made them low-cost potential adsorbents for the removal of dyes and many heavy metals ions from the industrial wastewater ${ }^{7-10}$.The present study was aimed to characterize the metal-binding ability of activated carbons derived from Phyllanthus Emblica tree bark.

\section{Preparation of Solutions}

\section{EXPERIMENTAL}

Potassium dichromate is used to prepare a standard stock solution by using double distilled water. Estimation of Chromium (VI) can be done by using a 1, 5-diphenylcarbazide method. The concentration

Rasayan J. Chem., 13(3), 1829-1833(2020)

http://dx.doi.org/10.31788/ RJC.2020.1335816 
RASĀYAN J. Chem.

Vol. 13 | No. 3 |1829-1833| July - September | 2020

of Cr (VI) metal ions analyses by using a UV-Visible spectrophotometer (model-117) at the wavelength of $540 \mathrm{~nm}$.

\section{Surface Modification of GAC}

$0.01 \mathrm{M}$ concentration of each chelating agent is used for the modification of the surface of activated charcoal. For the surface modification $200 \mathrm{ml}$ solution of chelating agent and 0.5 gram of activated charcoal prepared from Phyllanthus emblica tree taken in a reagent bottle and shaken for $3 \mathrm{hrs}$ at room temperature at $1000 \mathrm{rpm}$. Activated charcoal loaded with Sodium lauroyl sarcosinate, 2-Acrylamido-2methylpropane sulfonic acid designated as AC-PETB-SLS and AC-PETB-AMPSA.

\section{Batch Study}

The required amounts of standard solution were prepared from the known concentration of a stock solution of Chromium (VI) by diluting it with double distilled water. The $200 \mathrm{ml}$ of a prepared standard solution having various concentrations of $\mathrm{Cr}$ (VI) metal ions taken in reagent bottle and added 0.5 gram of activated charcoal prepared from Phyllanthus emblica tree and system is equilibrated by shaking the contents of the flask at room temperature for $3 \mathrm{hrs}$. The adsorbent and adsorbate were separated by filtration and filtrate were determined by spectrophotometer at $\lambda=540 \mathrm{~nm}$ against a reagent blank. The same experiments were carried out for loaded AC-PETB with various chelating agents.

The amounts of percentage adsorption were computed as follows:

$$
\% \text { Adsorption }=\left(\mathrm{C}_{\mathrm{o}}-\mathrm{C}_{\mathrm{e}}\right) / \mathrm{C}_{\mathrm{o}} \times 100
$$

Where in equation $\mathrm{C}_{\mathrm{o}}$ and $\mathrm{C}_{\mathrm{e}}$ represented the initial and equilibrium concentration $(\mathrm{mg} / \mathrm{L})$.

\section{Effect of pH}

The effect of $\mathrm{pH}$ can be studied by using $200 \mathrm{ml}$ of known concentration solution of $\mathrm{Cr}(\mathrm{VI})$ and 0.5 gram of adsorbent having a constant initial metal ions concentration and are shaken on a rotary shaker for about 3 hours at $1000 \mathrm{rpm}$. The result shows the maximum removal of $\mathrm{Cr}(\mathrm{VI})$ at $2 \mathrm{pH}$ by AC-PETB, AC-PETBSLS and AC-PETB-AMPSA as an adsorbent. It is observed that up to $\mathrm{pH} 2$ the increase in Cr (VI) removal percentage and then after decreases by increasing $\mathrm{pH}$ shows in Fig.-1.

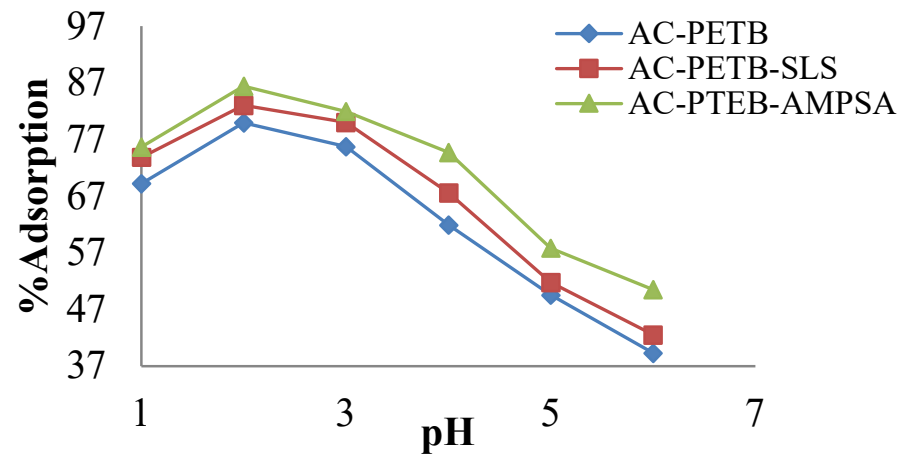

\section{Effect of Contact Time}

Fig.-1: Effect of $\mathrm{pH}$

The effect of contact time was studied by taking $200 \mathrm{ml}$ of the working volume of $\mathrm{Cr}$ (VI) and kept its $\mathrm{pH}$ 2.0 having an adsorbent dose 0.5 gram. It is found that at $1000 \mathrm{rpm}$ speed the removal percentage is rapid up to $160 \mathrm{~min}$ and thereafter it reached to equilibrium stage after that no further adsorption observed. Equilibrium time was found to be $300 \mathrm{~min}$ for the adsorption of $\mathrm{Cr}(\mathrm{VI})$. The effect of contact time was studied at room temperature $\pm 30^{\circ} \mathrm{C}$.

\section{Effect of Adsorbent Dose}

The adsorbent doses are varied from 0.2 gram to 1 gram to study the effect of adsorbent dose from the retrieval of hexavalent Chromium from aqueous solution at ph 2.0. Varying amount of adsorbent dose added in reagent bottle by taking $200 \mathrm{ml}$ working volume of known concentration of $\mathrm{Cr}$ (VI) solution and 
RASĀYAN J. Chem.

Vol. 13 | No. 3 |1829-1833| July - September | 2020

shaken for $3 \mathrm{hrs}$ at $1000 \mathrm{rpm}$ for 3 hours. It has been found that as the dose of adsorbent increases the percent removal of $\mathrm{Cr}(\mathrm{VI})$ also increases with an increase up to the saturation level.

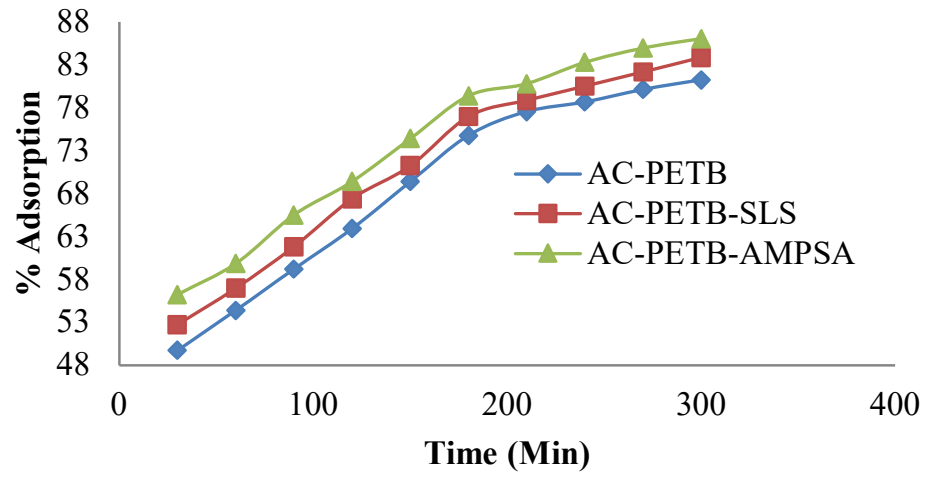

Fig.-2: Effect of Contact Time

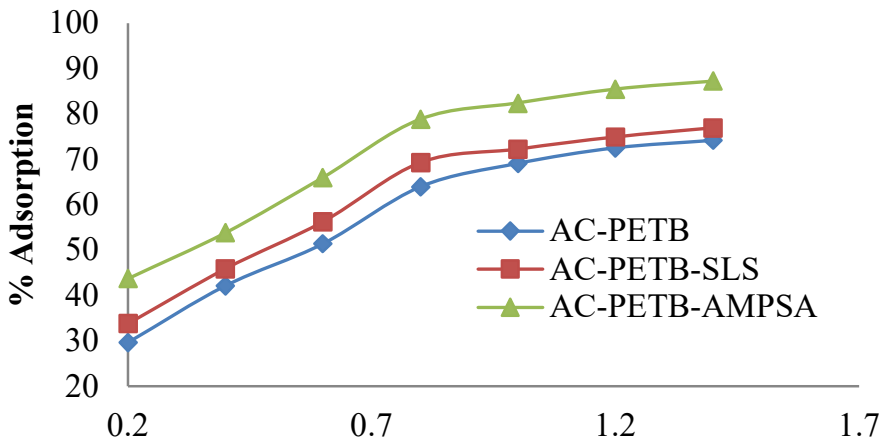

Adsorbent Dose(Gram)

Fig.-3: Effect of Adsorbent Dose

\section{Effect of Initial Metal Ion`s Concentration}

The effect of initial metal ion's concentration was carried out by increasing initial metal ions concentration and 0.5 gram of adsorbent AC-PETB, AC-PETB-SLS and AC-PETB-AMPSA. The $\mathrm{pH}$ of the solution made at $\mathrm{pH} 2.0$. The solution is shaken with adsorbent at $1000 \mathrm{rpm}$ having a contact time 3 hours. It is found that adsorption gets decreases when there is an increase in metal ion`s concentration.

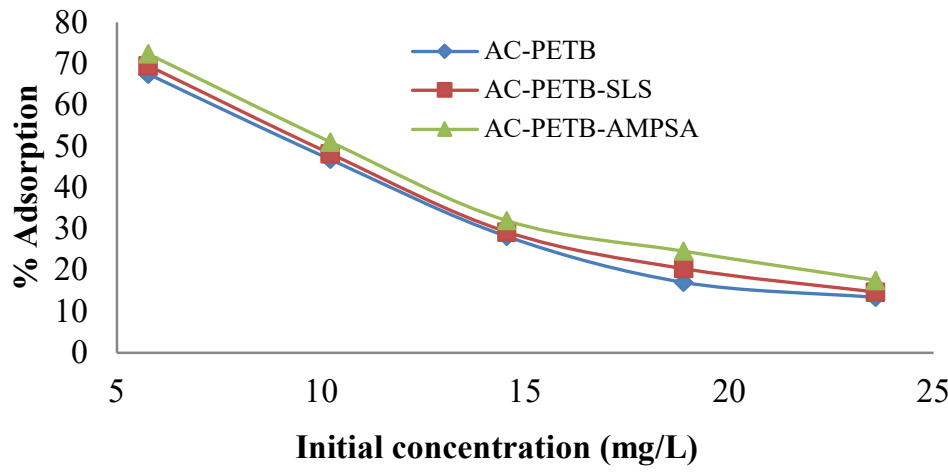

Effect of Temperature

Fig.-4: Effect of Initial Metal Ions Concentration

To study the effect of temperature the $\mathrm{pH}$ of the $\mathrm{Cr}(\mathrm{VI})$ solution kept at 2 having working volume $200 \mathrm{ml}$. This study carried out in the range from $30^{\circ} \mathrm{C}$ to $60^{\circ} \mathrm{C}$. The solution was shaken at $1000 \mathrm{rpm}$ for about 3 hours. As the temperature increases porosity increases and percent of adsorption increase up to a certain 
RASĀYAN J. Chem.

Vol. 13 | No. 3 |1829-1833| July - September | 2020

extent and then remains constant this is due to the chemisorptions process. In chemisorptions as the temperature increases adsorption increases up to a certain extent and then decreases while in the physisorption process as the temperature increases adsorption decreases. From the study, it was observed that the phenomenon was chemisorptions.

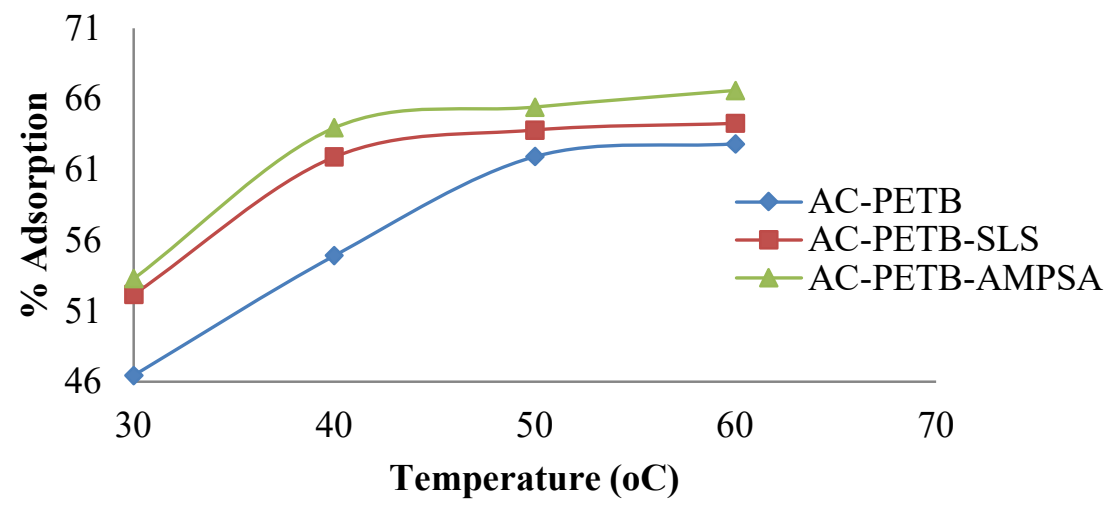

\section{Scanning Electron Microscopy}

Fig.-4: Effect of Temperature

The surface of the adsorbent was analyzed by scanning electron microscopy (SEM) to study the surface morphology of the adsorbent. Figure-4A shows small pores on the surface of the adsorbent which is used for the binding of metal ions on the surface of the adsorbent. SEM shows rough and porous structures of the adsorbent before metal ion's adsorption. Figure-4B shows drastic changes on the surface of the adsorbent after the metal ion's adsorption because of metal ion's adsorption. The pores are vanished due to the metal ion's adsorption on the surface of the adsorbent. This shows adsorbent has active sites for the adsorption of metal ion`s.

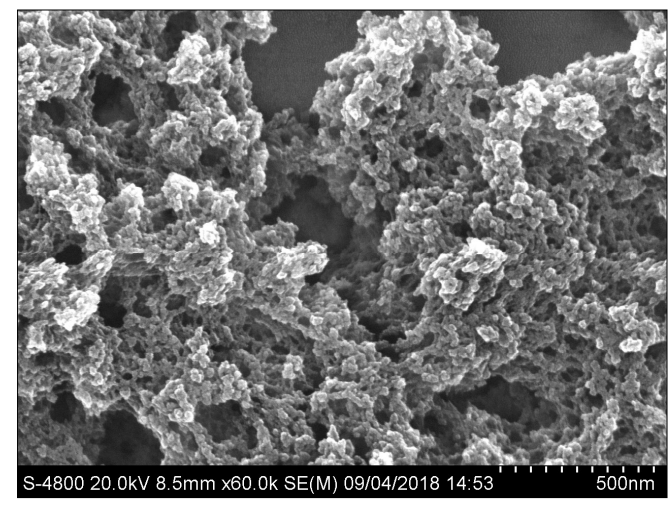

Fig.-4A: Before Metal Ion`s Adsorption

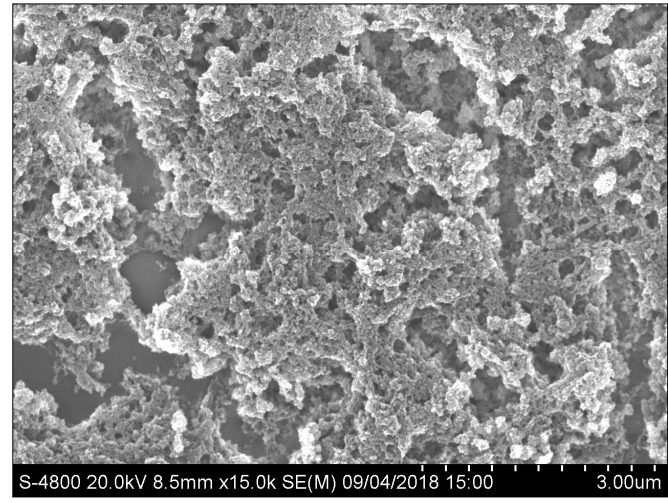

Fig.-4B: After Metal Ion`s Adsorption

\section{Adsorption Isotherm}

\section{Langmuir Adsorption Isotherm}

The monolayer adsorption mechanism was studied by using Langmuir adsorption isotherm, data shown in Table $1 . Q_{0}$ is adsorption capacity which is found to be nearly adsorption capacity of commercial activated carbon. The $\mathrm{R}_{\mathrm{L}}$ values found to be between 0 and 1 which shows a favorable adsorption process. This indicates that Langmuir adsorption isotherm is applicable for the removal of $\mathrm{Cr}(\mathrm{VI})$. The value $\mathrm{R}^{2}$ which is calculated from the Langmuir adsorption isotherm confirms the applicability of Langmuir adsorption isotherm.

\section{Freundlich Adsorption Isotherm}

The graph was plotted to study the multilayer adsorption for the removal of Chromium (VI) on ACPETB, AC-PETB-SLS and AC-PETB-AMPSA using Freundlich adsorption isotherm. The values obtained from the Freundlich adsorption isotherm are depicted in Table-1. Adsorption intensity $1 / \mathrm{n}<1$, indicates the applicability of Freundlich adsorption. 
RASĀYAN J. Chem.

Vol. 13 | No. 3 |1829-1833| July - September | 2020

Table-1: Adsorption Isotherm Constants

\begin{tabular}{c|c|c|c|c|c|c|c}
\hline \multirow{2}{*}{ System } & \multicolumn{4}{|c|}{ Langmuir Isotherm } & \multicolumn{3}{c}{ Freundlich Isotherm } \\
\cline { 2 - 8 } & $\mathrm{Q}_{\mathrm{o}}$ & $\mathrm{b}$ & $\mathrm{R}_{\mathrm{L}}$ & $\mathrm{R}^{2}$ & $\mathrm{~K}_{\mathrm{f}}$ & $1 / \mathrm{n}$ & $\mathrm{R}^{2}$ \\
\hline AC-PETB-Cr(VI) & 3.6900 & 0.2275 & 0.2906 & 0.942 & 1.271 & 0.300 & 0.998 \\
\hline AC-PETB-SLS-Cr(VI) & 4.9261 & 0.1926 & 0.3261 & 0.997 & 1.766 & 0.235 & 0.996 \\
\hline AC-PETB-AMPSA-Cr(VI) & 9.4339 & 0.0832 & 0.5284 & 0.998 & 2.366 & 0.171 & 0.999 \\
\hline
\end{tabular}

RESULTS AND DISCUSSION

The results show that activated charcoal prepared from Phyllanthus Emblica tree bark (AC-PETB) acts as a low-cost adsorbent for the removal of $\mathrm{Cr}(\mathrm{VI})$ metal ions. At $\mathrm{pH} 2$ removal of $\mathrm{Cr}$ (VI) found to be maximum due to the electrostatic attraction between ions present in the solution. The saturation time for the retrieval of $\mathrm{Cr}$ (VI) was found to be 180 minutes after that no adsorption of very little adsorption occurs. Temperature study shows that up to $50^{\circ} \mathrm{C}$ adsorption rate is higher after that it reaches the saturation level. Removal of hexavalent chromium from aqueous solution can be scaled up to the industrial level by using low-cost bio-adsorbent like Phyllanthus Emblica tree bark (AC-PETB).

\section{CONCLUSION}

1. Activated charcoal prepared from Phyllanthus Emblica tree bark (AC-PETB) was found to be lowcost adsorbent for the removal of $\mathrm{Cr}(\mathrm{VI})$. At initial stage removal of Chromium (VI) was found to be rapid after that it gets slowed down and reaches up to saturation level after $180 \mathrm{~min}$.

2. Among the Langmuir and Freundlich adsorption isotherm, Langmuir adsorption isotherm best fitted with the equilibrium data.

3. The maximum removal efficiency for the removal of $\mathrm{Cr}(\mathrm{VI})$ was found to be at $\mathrm{pH} 2$. Activated charcoal loaded with 2-Acrylamido-2-methylpropane sulfonic acid shows higher adsorption capacity than Sodium lauroyl sarcosinate and virgin activated carbon.

4. A result indicates that as the temperature, adsorption dose, contact time increases adsorption capacity increases while decreases with an increase in initial metal ions concentration.

\section{ACKNOWLEDGMENT}

We are very much thankful to the Principal of Shri Shivaji Arts, Commerce and Science College, Akot for permitting us research laboratory and providing necessary facility to carry out the research work.

\section{REFERENCES}

1. H. Joga Rao, P. King and Y. Prasanna Kumar, Rasayan Journal of Chemistry, 11(3), 1376(2018). DOI: 10.31788/RJC.2018.1134035

2. K. Velumani, P.E. Kumar and V. Sivakumar, Rasayan Journal of Chemistry, 9(2), 149(2016).

3. M. Kobya, Adsorption Science and Technology, 22(1), 51(2004), DOI: $10.1260 / 026361704323150999$

4. M. Kobya, E. Demirbas, M. A. Senturk, Bioresource Technology, 96(13), 1518(2005), DOI: $10.1016 /$ j.biortech.2004.12.005

5. C. Selomulya, V. Meeyoo, R. Amal, Journal of Chemical Technology and Biotechnology, 74, 111(1999), DOI: 10.1002/(SICI)1097-4660(199902)74:2<111::AID-JCTB990>3.0.CO;2-D.

6. A. K. Wanjari, International Journal of Pharmaceutical and Chemical Sciences, 2(1), 457(2013).

7. C. K. Ahn, D. Park, S. H. Woo, J. M. Park, Journal of Hazardous Materials, 164, 1130(2009).

8. S. Babel and T. A. Kurniawan, Chemosphere, 54(7), 951(2004). DOI: 10.1016/j.chemosphere.2003.10.001

9. A. K. Wanjari, Der Pharma Chemica, 8(18), 87(2016).

10. C. Moreno-Castilla, M.A. Alvarez-Merino, M.V. Lopez-Ramon, J. Rivera-Utrilla, Langmuir, 20(19), 8142(2004), DOI: 10.1021/la049253m

[RJC-5816/2020] 